\title{
Konvergensi dan Kompetisi Media Massa dalam Memenangkan Pasar di Era Media Digital di Makassar
}

\author{
Nurliah \\ Program Studi Ilmu Komunikasi \\ FISIPOL Universitas Mulawarman \\ Liah77@yahoo.com
}

\begin{abstract}
The aim of the research was to analyze the printed mass media in making use of new media (online media) in order that they are able to converge and compete in an attempt to seize market in order to reap the advertisements and readers in the digital media era in Makassar.The Research was conducted to the editors in Chief, reportage coordinators and the manager of online media in Makassar, i.e. Tribun Timur Makassar and Fajar. Informants were selected by using purposive sampling methode based on the consideration that those informants knew well of what was expected from the research. The methodes of collecting the data were observation, in-depth interview, and documentation. The data were analyzed using by qualitative analysis.The results reveal that mass media convergence could overcome the decrease of the number of readers on mainstream media since the distribution of news does no longer only rely on newspapers but also on online media. The presence of these online media is a part of conventional media aiming to strengthen the media function of media so that they could expand the reader networks through a wider range of the distribution of news. This is the answer to market demands in order to survive and win the market in digital media era in Makassar. Mass media competition is analyzed by using Niche theory in which the media compete in one another in the same ecological space to obtain the source of life support, i.e. capital, content, and audience. Capital (advertisement) is the primary source of support, so online media are seriously given attention in order that they give a large amount of turnover. However, the income obtained from advertisements is still low compared to that of newspapers since the form of competition is not really high. This is because the companies in Makassar do not give a big advertisement budget allocation in online media.
\end{abstract}

Key Words : Digital media, online media, convergence media, media competition.

\section{PENDAHULUAN}

\section{Latar Belakang}

Tahun 1990-an menjadi penanda revolusi teknologi komunikasi. Revolusi teknologi komunikasi ini menghadirkan peran internet sebagai media baru. Tidak sampai 20 tahun terjadilah pergeseran paradigma media yang bersifat global dan sangat fundamental. Pergeseran itu menyangkut produksi, penyimpanan dan 
penyebaran informasi digital secara global melalui jaringan internet (online). Melalui jaringan ini, setiap komputer mampu menerima dan mengirim teks, gambar, audio dan video dengan cepat dan murah. Inti dari teknologi digital adalah proses perubahan segala bentuk informasi (teks, suara, dan gambar) diencode ke dalam kode berisi digit 0 dan 1 (flew, 2002: 17 dalam Sri Hastjarjo). Teknologi digital ini melahirkan majalah digital, koran digital, hingga video digital.

Gencarnya masyarakat menggunakan internet untuk mendapatkan informasi, terhubung dengan jaringan sosialnya, hingga memproduksi informasi sendiri menyebabkan peran internet semakin penting. Kemampuan memadukan sebagai produsen dan konsumen (prosumen), membuat media massa tradisional terpicu untuk turut menggunakan media baru ini. Dalam bahasa Bill Kovach terjadi sebuah persilangan antara konsumen dan produsen atau prosumen (Kovach : 21). Mulai digemarinya situs berita online karena selain cepat terutama pula didistribusikan secara gratis. Pemakai internet di Indonesia saat ini sudah mencapai 25 persen dari total penduduk Indonesia (Tempo, edisi 5 April 2009).

Kemampuan media online mendistribusikan berita dengan gratis, lebih cepat, interktif dan saat itu juga (event on the making) dianggap media massa mainstream sebagai kondisi yang tepat untuk memperluas jaringan pembaca dan yang cukup penting menumbuhkan loyalitas. Sinergitas antara platform cetak dan online melahirkan kekuatan membentuk media konvergensi. Maka lahirlah apa yang sesuai gambaran Jhon V Pavlik bahwa media konvergensi adalah bersatunya semua bentuk komunikasi media ke sebuah bentuk elektronik, bentuk digital, yang digerakkan oleh komputer dan berfungsinya teknologi jaringan (Pavlik, 2006 : 134).

Media konvergen tak bisa dipungkiri dapat memicu kompetisi untuk dapat merebut pasar, entah iklan atau pembaca. Media konvensional pun kini berbondong-bondong membangun situs, membuat akun di situs jejaring sosial, hingga membuat blog. Hal ini tak lain merupakan upaya untuk meraup pembaca (readership) yang lebih beragam, juga menambah pundi-pundi keuangan lewat 
iklan di media online. Di lingkungan yang sangat kompetitif saat ini, iklan di media online dianggap lebih efektif dengan jangkauan audiens yang lebih luas dan besar. Media online yang lebih interaktif, lebih digemari sebagai media pemasaran baru. Fitur yang unik telah menjadi populer di kalangan pengguna (user/partisipan) dan pengiklan.

Jika mencermati kompetisi media massa di Makassar, dapat dikaji dengan teori Niche (niche dapat diartikan sebagai celung atau ruang kehidupan). Teori Niche bertitik tolak dari pandangan ekologis dalam melihat persaingan antarmedia. ibaratnya proses kompetisi antarindustri media ini sebagai proses ekologis (bioecology/human ecology) (Kritiya Kartini mengutip John Dimmick dan Eric Rothenbuhler, 1984:107).

Melihat lebih jauh kompetisi antarmedia, John Dimmick dan Erick Rothenbuhler dalam Kristiya Kartika (1996) menggunakan pendekatan kompetisi antarsuratkabar untuk mempertahankan kehidupannya selalu berusaha mendapatkan sumber penunjang yang cukup. Sedangkan kenyataannya, sumber penunjang tersebut jumlahnya terbatas dan diperebutkan oleh media yang terus bertambah jumlahnya.

Adapun sumber penunjang media adalah: Capital (pemasukan iklan, omzet sirkulasi dan lain-lain), content (isi), audience (khalayak sasaran) Dari ketiga sumber tersebut, capital, khususnya pemasukan dari sektor iklan merupakan sumber penunjang yang utama (Kartika, 1996). Namun, seiring dengan perkembangan teknologi komunikasi, media massa mulai mempertimbangkan audiens/khalayak.

Berdasarkan latar belakang di atas, penelitian ini diberi judul “KONVERGENSI DAN KOMPETISI MEDIA MASSA DALAM MEMENANGKAN PASAR DI ERA MEDIA DIGITAL DI MAKASSAR"

\section{Rumusan Masalah :}


1. Bagaimana media konvensional khususnya koran memanfaatkan internet untuk memenangkan pasar di era digital?

2. Bagaimana konvergensi media konvensional dengan media online mampu meredam menurunnya iklan dan pembaca di era media digital?

3. Bagaimana bentuk kompetisi media massa dalam memenangkan pasar guna merebut jumlah pembaca dan pengiklan di era media digital di Makassar?

\section{Tujuan Penelitian}

Pada dasarnya penelitian ini bertujuan untuk mengetahui bagaimana media cetak memanfaatkan internet (new media), dan apakah konvergensi media konvensional dengan media online mampu meredam menurunnya iklan, sirkulasi dan pembaca di era media digital sehingga mampu berkompetisi dan memenangkan pasar di era digital.

\section{Manfaat Penelitian}

Dapat dimanfaatkan sebagai bahan acuan bagi perusahaan media massa yang melakukan konvergensi agar lebih meningkatkan pengembangan platform media mereka baik itu platform cetak, online, dan lainnya sehingga dapat memenangkan kompetisi di ranah digitaliasi media.

\section{TINJAUAN PUSTAKA}

Konvergensi antara teknologi komputer, telekomunikasi, elektronika, media massa, dengan seni inilah yang menumbuhkan keniscayaan New Media (media online). Ana Nadhya Abrar dalam http://epistoholica.blogspot.com/search menyebutkan pelbagai keuntungan, antara lain : (a) audience control, di mana masyarakat bisa leluasa memilih berita yang ingin mereka peroleh, (b) nonlinearity, memungkinkan setiap berita dapat berdiri sendiri sehingga masyarakat tidak harus membaca secara berurutan untuk memahaminya, (c) storage and retrieval, berita dapat disimpan dan bisa diakses kembali secara mudah oleh masayakat, (d) unlimited space, berita jauh lebih lengkap ketimbang media lainnya karena tidak terbatasnya ruang yang tersedia, (e) immediacy, berita 
bisa mampu segera disampaikan secara langsung kepada masyarakat, (f) multimedia capability, berita dapat disampaikan berupa teks, suara, gambar, video dan komponen lainnya, dan (g) interactivity, terbukanya peningkatan partisipasi masyarakat dalam penyajian setiap berita.

Persaingan atau kompetisi media massa dapat ditelaah dari sudut ekologi. Aulia Andri mengutip Levin (dalam Sendjaja, 1996) menguraikan faktor-faktor yang dapat dilihat dalam mencermati ekologi (lingkungan hidup) media massa dan ketatnya persaingan media massa. Pertama, sumber penunjang kehidupan atau iklan yang disebut niche breadth. Kedua, faktor penggunaan sumber penunjang kehidupan atau rubrik yang disebut niche overlap.

Sedangkan pandangan Kotler sendiri melihat bahwa para pelanggan (konsumen) semakin sulit dipuaskan. Alat-alat yang mendasari sebuah marketing mix (marketing mix adalah seperangkat alat marketing yang digunakan sebuah perusahaan untuk mengejar obyek marketingnya dalam sebuah sasaran pelanggan). Dalam gambar 2 McCarthy mengklasifikasikan alat-alat ini dalam empat kelompok yang disebutnya sebagai Ps of Marketing yakni product (produk), price (harga), place (tempat/lokasi), dan promotion (promosi). (Kotler : $2000: 10)$

\section{METODE PENELITIAN}

\section{Obyek Penelitian}

Penelitian ini dilakukan di dua media massa yang tergabung dalam dua kelompok besar yang terbit di Makassar yakni Fajar Tribun Timur.

\section{Tipe Penelitian}

Penelitian ini menggunakan paradigma penelitian deskriptif kualitatif di mana peneliti berusaha mendeskripsikan atau mengkonstruksi hasil wawancara mendalam terhadap objek penelitian.

\section{Informan Penelitian}

Informan adalah Pemimpin Redaksi, Koordinator Liputan dan penanggung jawab media online. 


\section{Jenis dan Sumber Data}

Data primer dalam penelitian bersumber dari informasi yang diberikan oleh para informan melalui wawancara mendalam dan observasi. Sedangkan data sekunder diperoleh dari buku, majalah, surat kabar serta literatur-literatur yang berkaitan dengan masalah penelitian.

\section{Fokus Penelitian}

Penelitian ini difokuskan pada pengelola media massa cetak yang terbit di Kota Makassar. Aspek yang diteliti dari pengelola media tersebut adalah yang berkaitan dengan kompetisi dan konvergensi media massa cetak menuju era digital.

\section{Alat Penjaring Data}

Peneliti menjadi instrumen utama dalam memperoleh data di lapangan dengan menggunakan dua macam teknik, yakni : (1) Observasi dan (2) wawancara mendalam terhadap informan dengan bantuan alat perekam, alat tulis, dan alat dokumentasi.

\section{Teknik Pengumpulan Data}

Data yang diperlukan dalam penelitian ini diperoleh melalui teknik pengumpulan data yaitu observasi, wawancara mendalam, studi pustaka, dan dokumentasi.

\section{Teknik Analisis Data}

Data dalam penelitian ini menggunakan analisis data model interaktif Miles dan Huberman (dalam Islami, 2001) yaitu terdapat tiga proses yang berlangsung secara interaktif yaitu reduksi data, penyajian data, dan menarik kesimpulan / verifikasi. 


\section{HASIL PENELITIAN DAN PEMBAHASAN}

\section{Media Tradisional Memanfaatkan Internet (New Media)}

Dua media massa di Makassar yakni Tribun dan Fajar mengadopsi teknologi baru dalam sistem pengelolaan medianya dengan membentuk platform online dan divisi khusus yang menangani media online mereka. Dari informasi empat informan di kedua media tersebut diperoleh gambaran bahwa kehadiran media online yang bersinergi dengan platform media lainnya sangat penting. Pemanfaatan media online merupakan sebuah inovasi dalam mengadopsi teknologi komunikasi yang terus berkembang. Internet yang dipadu dengan personal komputer, laptop maupun telepon cerdas seperti blackberry, PDA, Ipod menjadi kreasi yang penting sebagai salah satu alat distribusi berita selain agen atau loper koran. Jangkauan pembaca semakin luas dan beragam dengan penambahan alat distribusi.

Tribun Timur yang memiliki Sumber Daya Manusia (SDM) yang minim, menggunakan teknologi baru tersebut untuk menambah bentuk media selain koran, dengan tak perlu terlalu banyak merekrut pekerja. Tribun menekankan bahwa kehadiran teknologi dimanfaatkan semaksimal mungkin melalui satu ruang redaksi (single newsroom) dengan banyak platform media (multiplatform). Anggaran mampu ditekan melalui pekerja yang minim dengan hasil kerja yang maksimal. Sebab, satu jurnalis mempunyai tugas sebagai jurnalis online, jurnalis koran, jurnalis televisi hingga jurnalis radio. Sehingga misi Tribun dengan hadirnya berbagai macam bentuk media dapat terwujud yakni mampu memenuhi keinginan pembaca atau pelanggannya tak mengeluarkan anggaran yang lebih besar.

Sesuai tesis Pavlik bahwa keberadaan teknologi baru di media massa untuk mempertahankan pemirsa sekaligus juga menambah pemirsa baru. Tujuan itulah yang ingin didapatkan dua media massa tersebut. Walaupun informan Fajar sangat yakin meski internet merebak tak menggangu tiras Fajar. Bahkan cenderung naik ketika ada peristiwa tertentu. Namun sedikit banyak kehadiran media online Fajar 
dimaksudkan agar kompetitor tak mengganggu pembaca dan terutama pula tak mengganggu bisnis media Fajar Grup. Sedangkan informan dari Tribun secara terus terang mengatakan kehadiran portal berita untuk memenuhi keingin pembacanya. Maka tak heran jika situs jejaring sosial gencar digunakan pula untuk mempromosikan berita terbaru mereka.

\section{Konvergensi Media Massa Di Era Media Digital}

Kedua media yang menjadi obyek penelitian ini sudah melakukan konvergensi yakni selain mendistribusikan media lewat media cetak juga dengan media online yang mana mesin penggeraknya adalah internet. Sehingga sesuai dengan teori Pavlik dan Friedman, terjadi sebuah kolaborasi dan koneksi antara media cetak dan elektronik. Berbagai perangkat sudah saling bersinergi. Untuk konvergensi ini informan dari Tribun menekankan sebagai unsur efisiensi dan efektivitas kerja Tribun.

Secara jujur informan Tribun menyadari mereka minim sumberdaya. Maka, meskipun memilki sedikit sumberdaya manusia, namun dengan satu newsroom (redaksi) mereka dapat mengerjakan banyak platform media. Sementara informan dari Fajar menekankan visi Fajar adalah multimedia dimana segala bentuk media dapat diproduksi perusahaan Fajar Grup, sehingga layaknya swalayan pelanggan tinggal memilih apa yang sesuai dengan seleranya.

Kehadiran media online ini menurut informan dari Tribun sangat bermanfaat dan mengubah kinerja mereka. Yang pasti adalah kemudahan bagi jurnalis untuk mengirim berita maupun foto dengan cepat melalui beragam alat komunikasi yang kian canggih. Informan dari Fajar memudahkan pembaca atau pemirsa memilih berita apapun yang menjadi seleranya. Tinggal mengklik, berita sudah ada di hadapan pembaca. Keberadaan teknologi ini menjawab teori Friedman bahwa hanya orang kreatif dan yang mampu beradaptasi dengan teknologi yang dapat menggerakkan globalisasi dunia.

Implikasi yang ditimbulkan media konvensional (koran) khususnya Tribun 
Fajar yang berintegrasi dengan media baru (online) dapat dilihat dari :

a. Tribun Timur

1. Khalayak pengakses internet dapat memilih berita apa yang sesuai dengan selera dan tujuan informasi yang diinginkannya karena telah tersedia fitur berita hiburan, terkini, teknologi, hingga berita daerah maupun reportase dari warga.

2. Karena berita dihadirkan secara follow up, maka terserah pengakses ingin membaca berita yang mana terlebih dahulu. Karena indeks berita tersedia begitupun hyperlink dengan sejumlah berita terkait.

3. Berita-berita yang pernah diliput jurnalis Tribun dapat kembali diakses jika khalayak ingin kembali mengaksesnya. Ada mesin pencari berita, indeks berita terdahulu dan hyperlinknya.

4. Berita apapun dari media manapun dapat diperoleh karena sejumlah situs berita di-link-kan dengan website Tribun Timur.

5. Berita yang dihadirkan per menit karena mengusung karakter media yang realtime news. Jurnalis yang berada di lapangan telah dilengkapi foto, telepon cerdas, dan laptop sehingga ketika ada peristiwa terjadi tinggal mengirim ke uploader Tribun.

6. Tribun dapat membuat e-radio dan e-tv tanpa perlu menghadirkan teknologi radio dan televisi. Hanya memasukkan software ke situs berita Tribun, maka fitur program radio dan televisi dapat dinikmati khalayak pengakses situs berita Tribun sekaligus juga menikmati berita terbaru dan berita versi koran (e-paper).

7. Berita dapat ditanggapi khalayak pengakses situs berita Tribun. User dapat pula mengusulkan berita, meliput berita, hingga mengkritik berita yang ada karena tersedia chat room melalui facebook Tribun, twiiter Tribun, Yahoo Massanger Tribun, dan email Tribun.

\section{b. Harian Fajar}

1. Pengakses portal berita Fajar dapat memilih berita apa yang sesuai 
2. dengan selera informasi yang diinginkannya karena telah tersedia fitur berita aktual, hiburan, teknologi, hingga berita dari daerah.

3. Pengakses website Fajar dapat membaca berita yang mana terlebih dahulu. Karena indeks berita tersedia begitupun hyperlink dengan sejumlah berita terkait.

4. Berita-berita yang pernah diliput jurnalis Fajar dapat kembali diakses jika khalayak ingin kembali mengaksesnya. Ada mesin pencari berita, indeks berita terdahulu dan hyperlinknya.

5. Berita apapun dari media tertentu dapat diperoleh karena sejumlah situs berita di-link-kan dengan website Fajar.

6. Berita yang dihadirkan realtime news karena jurnalis yang berada di lapangan telah dilengkapi foto, telepon cerdas, dan laptop sehingga ketika ada peristiwa terjadi tinggal mengirim ke staf uploader Fajar.

7. Fajar grup telah menjalankan perusahaan yang multimedia sehingga selain koran dan internet juga masyarakat dapat memperoleh informasi melalui TV Fajar dan Radio Fajar. Berita Fajar dalam versi internet dapat dinikmati melalui PDF Fajar.

8. Interaktivitas Fajar dapat dilakukan melalui komentar pada berita karena disediakan kolom untuk menanggapi berita.

\section{Kompetisi Media Online dalam Memperebutkan Pasar di Makassar}

Kompetisi ini dapat dijelaskan dalam teori niche (ekologi media) bahwa lingkungan media berkenaan dengan hubungan timbal balik antara media massa dengan lingkungan penunjangnya. Fajar dan Tribun berkompetisi di lingkungan yang sama karena merupakan media umum lokal yang membidik berita yang sama. Sehingga dari isi, iklan, hingga khalayak pembaca memiliki segmen yang sama. Yang membedakan kemampuan membuat inovasi berita atau rubrikasi yang unik dan menarik sehingga mendatangkan pembaca dan pengiklan.

Begitupun dengan lahirnya media online, maka pertarungan memperebutkan pasar pada ruang ekologi yang sama semakin tajam dan sengit. 
Meski sebelumnya Fajar lebih dahulu mendirikan media online namun dihentikan. Barulah ketika Tribun gencar mempromosikan kehadiran media online mereka pada tahun 2007, Fajar tak membuang-buang waktu untuk kembali menghidupkan media onlinenya pada 2008. Walaupun Fajar mengatakan bukan karena mengikuti media pesaingnya, namun dapat dibaca dengan jelas bahwa dihidupkannya kembali media online Fajar tak lain agar Tribun tak sendirian di jagat media digital lokal.

Melihat strategi yang dilakukan Tribun dan Fajar dalam memanfaatkan internet sudah jitu jika melihat gambaran Michael Porter yakni memanfaatkan teknologi dan menawarkan produk yang bervariasi dengan membangun situs berita online selain tetap mempertahankan cetak. Namun keunggulan kompetisi yang berkelanjutan hanya mampu dilakukanTribun. Dengan mengungguli tawaran produknya di atas rata-rata. Tribun Timur membangun divisi khusus Tribun Online, meskipun Fajar juga membuat divisi khusus namun dalam hal penanganan berita online Fajar tidak tergarap dengan baik.

\section{PENUTUP}

\section{Kesimpulan}

Berdasarkan penelitian yang telah dilakukan dapat disimpulkan sebagai berikut :

1. Kehadiran media online ini sebagai bagian dari media konvensional yang hadir untuk memperkuat fungsi media konvensional agar dapat memperluas jaringan pembaca melalui distribusi berita yang lebih beragam.

2. Konvergensi yang mengintegrasikan tiga fitur unik yakni kemampuan multimedia berdasarkan platform digital, kualitas interaktif media online dan penataan fitur-fitur media massa konvensional mengatasi merosotnya jumlah pembaca (readership) terhadap koran.

3. Menambah platform cetak dengan media online melalui situs berita online, sedikit banyak mampu menaikkan jumlah pembaca pada media konvensional khususnya koran karena distribusi berita tak lagi hanya mengandalkan koran tetapi juga media online. 
4. Mencermati kompetisi media massa di Makassar, dapat dikaji dengan teori Niche. Kehadiran media online di dua media lokal ini membuat persaingan di antara mereka semakin tajam. Tak hanya berebut pembaca yang sama, juga berebut iklan dan membuat berita yang paling banyak dibaca masyarakat baik di media cetak maupun di media online.

\section{SARAN}

1. Secara praktis, perusahaan media konvensional yang telah membangun situs berita online perlu mengoptimalkan kinerja divisi media online dengan membangun divisi dan staf khusus. Meningkatkan kualitas dan kuantitas karya jurnalistik di media online sehingga menarik minat pembaca dan pengiklan.

2. Secara akademik, kalangan akademisi lebih mengembangkan lagi tentang kompetisi dan konvergensi media online dengan media cetak, namun dikaji dari aspek lain baik itu kebijakan redaksi media online, tingkat pemasukan iklan, ataupun juga keberlangsungan media online dalam praktik jurnalisme kontemporer.

\section{DAFTAR PUSTAKA}

Abrar, Ana Nadya. 2003. Teknologi Komunikasi Perspektif Ilmu Komunikasi. LESFI. Yogyakarta.

Achmad, AS. 1990. Manusia dan Informasi. Lembaga Penerbitan Universitas Hasanuddin, Ujung Pandang

Friedman, Thomas. 2006. The World Is Flat. Dian Rakyat, Jakarta

Kartajaya, Hermawan. 2010. Connect! Surving New Wave Marketing. PT Gramedia Pustaka Utama, Jakarta

Kotler, Philip. 2000. Marketing Management, Millenium Edition. Pearson Custom Publishing, New Jersey, Amerika. 
Kovach, Bill dan Rosenstiel, Tom. 2006. Sembilan Elemen Jurnalisme. Yayasan Pantau, Jakarta

Little John, S.W. 1995. Theories of Human Communication (Fifth Edition). Wadsworth publishing Company, Belmont California

Little John, S.W dan Foss, Karen A. 2009. A Theories of Human Communication (Ninth Edition). Salemba Humanika, Jakarta.

McQuail, Dennis. 1996. Teori Komunikasi Massa. Diterjemahkan oleh Agus Darma dan Aminuddin Ram. Erlangga, Jakarta

Pavlik, V John. 1996. New Media Teknologi : Cultural and Commercial Perspectives. Columbia University Press, New York

Pavlik, V John. 2008. Media In The Digital Age. Columbia University Press, New York

Porter, Michael E. 2001. Journal Harvard Bussines Review. Harvard University, Boston.

Rogers, M. Everett. 1986. Communication Techonology; The New Media in Society. The Free Press, New York

Santana, Septiawan, 2000. Jurnalisme Kontemporer. Yayasan Obor, Jakarta

Sendjaja, Sasa D, 1996. Teknologi dan Industri Media Massa di Indonesia : Menuju Era Niching dan Networking

Kartika, Kristiya. 1996. Ekologi Media : Persaingan Antar Industri Surat Kabar Dalam Memperebutkan Iklan, Tesis S2 Universitas Indonesia, Jakarta. 